\title{
Meditation Study with Data Analytics
}

\author{
Hong Lin* \\ Department of Computer Science and Engineering Technology, University of Houston-Downtown, USA
}

Submission: March 16, 2017; Published: April 24, 2017

*Corresponding author: Hong Lin, Department of Computer Science and Engineering Technology, University of Houston-Downtown, Texas, USA, Email: linh@uhd.edu

\section{Introduction}

Is Chan (Zen) Still Relevant in 21st Century? What do you get in the studies of Chan ontology, history, Chan's reflections on Buddhism, Taoism and Confucianism, Chan utterances and debates, Chan and mystics, and Chan poems and drawings? What is your mindset when thinking about Chan in modern societies? Chan is clearly a philosophy that impacts human are view about the essence of science and relates scientific studies to the contemplation of its performer-human. As a matter of fact, transcendental meditation [1], a spiritual development technique, which was popularized by former Hindu ascetic Maharishi Mahesh Yogi has gained popularity in the west during the 1960's [2]. We envision that by studying Chan with data analytics, we can help clarify the basic concepts of from pragmatic point of view.

As NIH program director Emmeline Edwards shared: "This sentiment seems to be shared widely by the scientific community and the public at large- there has been a growing interest in meditation practices; they are practiced in multiple forms (with and without movement); and they are used for multiple reasons including enhancing the quality of life, reducing psychological stress, and improving health outcomes. Meditation has been practiced since ancient times as a component of religious traditions and beliefs. There are, however, various styles of meditation practices; all include some training of the mind and self-induction of a mode of consciousness to realize some benefit".

Walsh and Shapiro refer to meditation as a "family of self-regulation practices that focus on training attention and awareness in order to bring mental processes under greater voluntary control and thereby foster general mental well-being and development and/or specific capacities such as calm, clarity, and concentration". Such regulating training of brain activities should entail some traces in physiological signals. One of the questions to answer might be whether we can build some brain state models using electroencephalographic (EEG) data. Much of the capability and technology is available now to implement all these thoughts. We may not be able to know exactly what you are thinking, but we can gather brainwave data and make it available for analysis. The methods may still be somewhat primitive and the technology in its infancy, but never the less, with only a few inexpensive off the shelve parts and a little ingenuity we can create a device that is capable of sensing body conditions and even read brainwaves.

One approach is to study finite differences within the minds of those practicing meditation, and those who do not. Such an endeavor is an avenue towards modeling a wide range of brain states [3]. The combination of electroencephalographic data with modeling methods in fields such as data mining and bioinformatics could be used to prove that subjects in a state of transcendental meditation are in a verifiable and observable state of mind that can be monitored and predicted [1]. Experiments found that cancer patients that practiced meditation experienced higher well-being levels, better cognitive function and lower levels of inflammation than a control group [4].

The primary motivation behind this is to know what signals the brain produces does under certain situations and to know how these signals are consciously manipulated via controlled thoughts. Additionally it is desirable to know if there is a way to enhance studying and learning abilities and being able to retain more information. A direct benefit of this study will be to extend psychology to develop new methods for healing various mental diseases. This objective is feasible because meditation is efficient in training human self-control since its goal is having one's every whim under observation. Through this study, it is anticipated to start a campaign to establish "measurable" meditation methods, applying scientific methodology to mind-body practices at large, or even making spiritual activities "tangible".

We measured an experienced meditator's brainwaves while meditating and compared them to several other states including idle and talking. We found prominent differences between the experienced meditator's brainwaves and those of other states. The experienced meditator's brainwaves clearly displayed a stable state most of the time, as shown in Figure 1a. However, during certain times after the initial meditation stage, extraordinary high waves were observed, as shown in Figure 1b. 


\section{Biostatistics and Biometrics Open Access Journal}

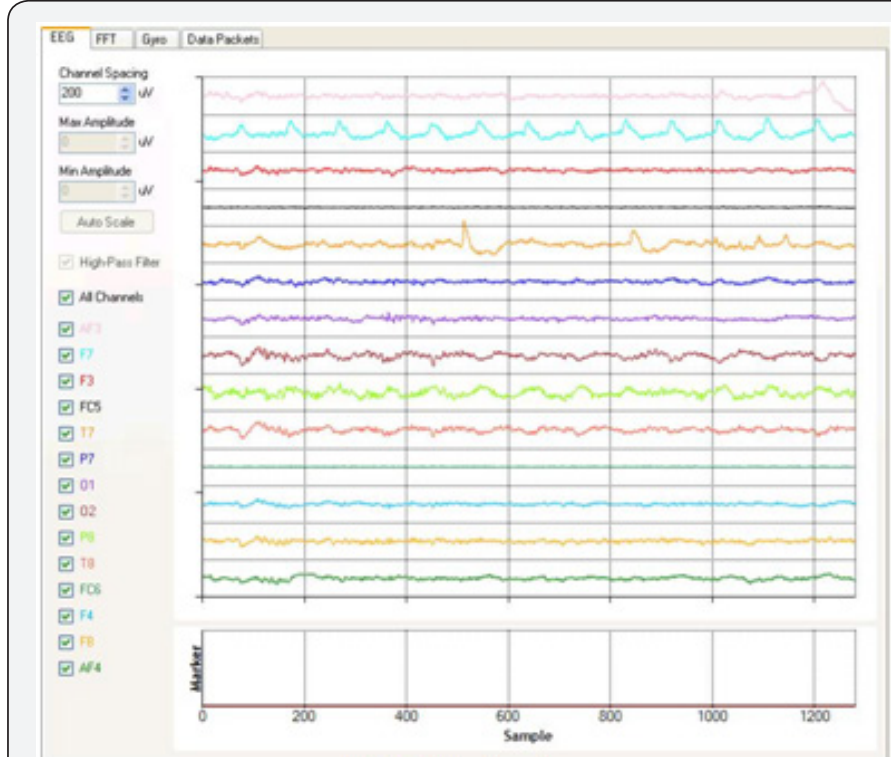

(a) Meditating 1

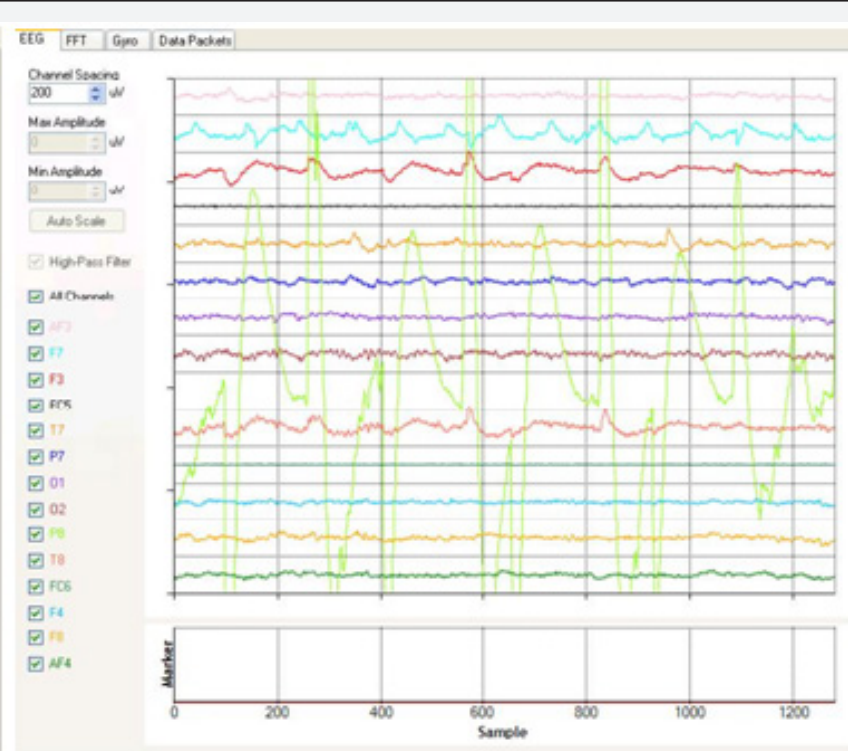

(b) Meditating 2

Figure 1: An Experienced Meditator's Brain Waves.

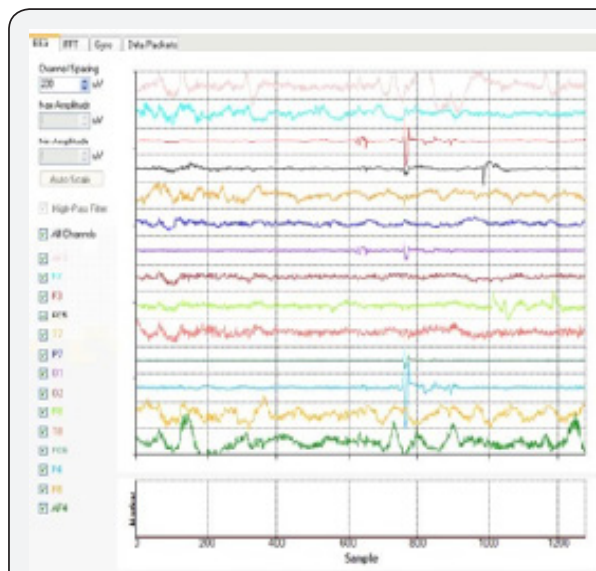

(a) Idle

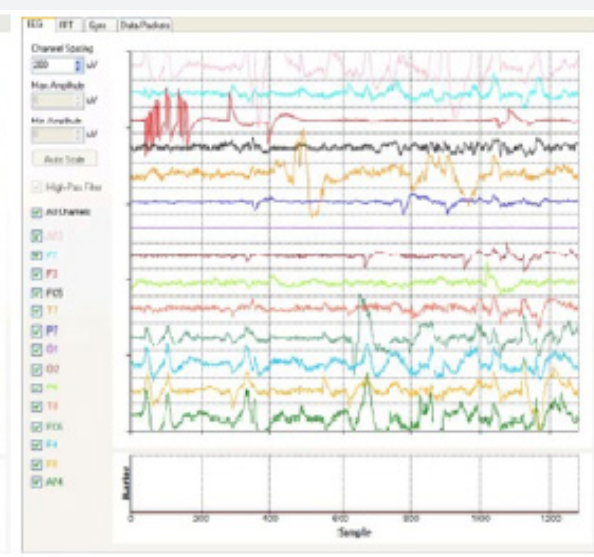

(b) Talking

Meditation

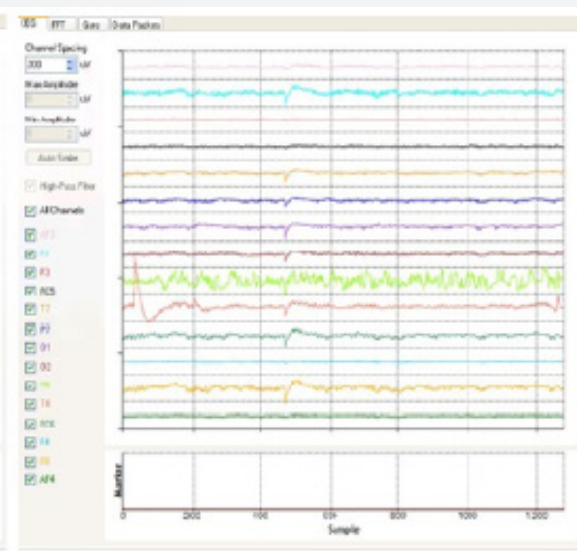

(c) Inexperienced

Figure 2: Brain Waves of Other States.

Figure 2 shows the brainwaves of idle, talking, and meditating from an inexperienced meditator. We can clearly see that the irregularities of these states are higher than the experienced meditator's state, especially the idle and the talking states. The inexperienced meditator showed some similarity to the state shown in Figure 1a but it didn't show the features in Figure $1 \mathrm{~b}$. This initial study indicates that trained meditators can demonstrate regularity during meditation practice. The regularity observed in the brain waves of meditation state suggests that entropy might be a right feature to use in the classification of brain states including meditation state. We tested a set of parameters and classification models using sample entropy. Sample entropy tends to measure the level of chaotic complexity of a time series data. We observed that for sample entropy the misclassification rates decrease when the time length increases. This makes sense according to the nature of sample entropy.

We exhibit the plots of sample entropy with different time lengths and embedding lags in Figure 3. In the plots, the sample entropy in talking is represented by triangles. Circles stand for the sample entropy in mediation, and rectangles are sample entropy in the idle state. Black filled shapes mark the misclassified data. We can see that with the increasing time length, sample entropy from different brain states tend to be more separated. We also notice that embedding lag becomes less influential when time length increases. Tree bagging, again, gives the smallest misclassification rates in most cases. This case study indicates that sample entropy provide a solid base to classify different brain states using original EEG data. 


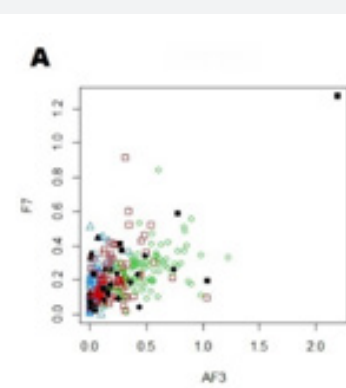

D

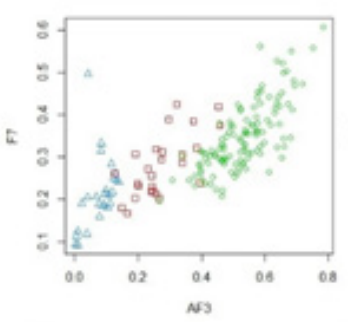

N3

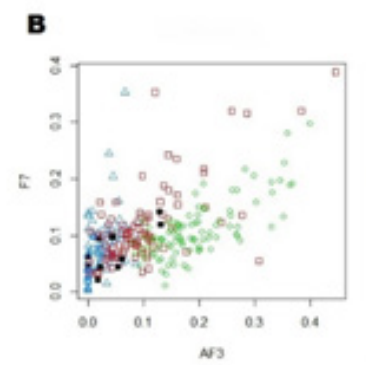

E

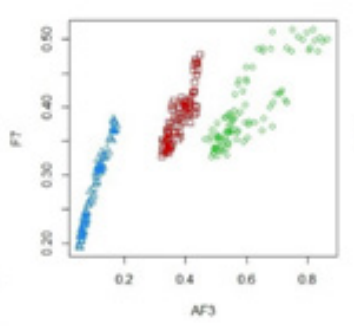

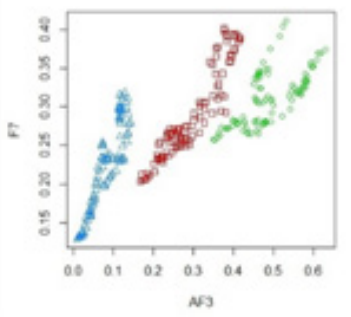

$\mathbf{F}$

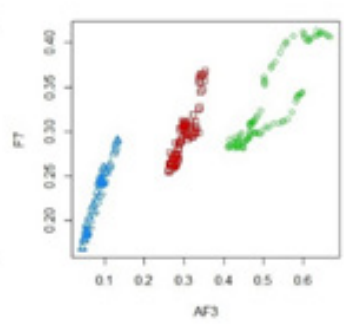

Figure 3: Sample Entropy with Different Parameters.
d. Time $=10 \mathrm{~s}$, Lag $=4$
e. Time $=60 \mathrm{~s}, \mathrm{Lag}=4$
a. Time $=1 \mathrm{~s}, \operatorname{Lag}=4$
b. Time $=1 \mathrm{~s}$, Lag $=1$
c. Time $=30$ s, $\operatorname{Lag}=4$

\section{References}

\section{Conclusion}

In conclusion, the meditation research is one sample case to reach out to the high end applications of EEG data analysis in understanding human brain states and assisting in promoting human healthcare. Some devotees to the practices of transcendental meditation have shown the ability to control these brain states. We want to numerically prove or disprove this assumption; the analysis of these states could be the initial step in a process to first predict and later allow individuals to control these states. We hope through systematic studies of meditation, we can make meditation a technologically approachable activity and thus accessible to a larger population.
1. Davidson RJ, Kabat-Zinn J, Schumacher J, Rosenkranz M, Muller D, et al. (2003) Alterations in Brain and Immune Function Produced by Mindfulness Meditation. Psychosom Med 65(4): 564-570.

2. Holzel BK, Carmody J, Vangel M, Congleton C, Yerramsetti SM, et al. (2011) Mindfulness practice leads to increases in regional brain gray matter density. Psychiatry Res 191(1): 36-43.

3. Lin H (2010) Measurable Meditation, Proceedings of the International Symposium on Science 2.0 and Expansion of Science (S2ES 2010), the $14^{\text {th }}$ World Multiconference on Systemics, Cybernetics and Informatics (WMSCI 2010). Orlando Florida, USA, 29: 56-61.

4. Oh B, Butow P, Mullan B, Clarke S, Beale P, et al. (2009) Impact of medical Qigong on quality of life, fatigue, mood and inflammation in cancer patients: a randomized controlled trial. Ann Oncol 21(3): 608614.

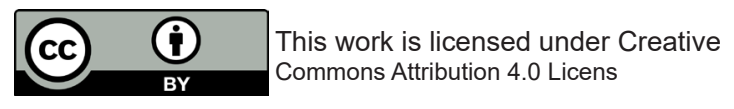

Your next submission with Juniper Publishers will reach you the below assets

- Quality Editorial service

- Swift Peer Review

- Reprints availability

- E-prints Service

- Manuscript Podcast for convenient understanding

- Global attainment for your research

- Manuscript accessibility in different formats

( Pdf, E-pub, Full Text, Audio)

- Unceasing customer service

Track the below URL for one-step submission https://juniperpublishers.com/online-submission.php 